\title{
Hetero-helicenes Synthesis Through 1,3-Dipolar-Cycloaddition of Sydnones with Arynes: Synthesis, Origins of Selectivity and Application to pH Triggered Chiroptical Switch with CPL-sign Reversal
}

\author{
Expédite Yen-Pon, ${ }^{[a]}$ Floris Buttard, ${ }^{[b], \perp}{ }^{\perp}$ Lucas Frédéric, ${ }^{[a]},{ }^{\perp}$ Pierre Thuéry, ${ }^{[c]}$ Frédéric Taran, ${ }^{[a]}$ Grégory \\ Pieters, ${ }^{[a], *}$ Pier Alexandre Champagne, ${ }^{[b], *}$ Davide Audisio ${ }^{[a], *}$ \\ [a] Université Paris-Saclay, CEA, Service de Chimie Bio-organique et de Marquage, DMTS, 91191, Gif- \\ sur-Yvette, France \\ ${ }^{[b]}$ Department of Chemistry and Environmental Science, New Jersey Institute of Technology, Newark, \\ NJ, USA, 07102 \\ ${ }^{[c]}$ Université Paris-Saclay, CEA, CNRS, NIMBE, 91191 Gif-sur-Yvette, France \\ ${ }^{\perp}$ These authors (F. B. and L. F.) contributed equally
}

\begin{abstract}
The regioselective access to hetero-helicenes through 1,3-dipolar cycloaddition of sydnones with arynes is described. Novel access to sydnones and poly-(hetero)aromatic aryne precursors allowed the introduction of chemical diversity over multiple positions of the helical scaffolds. The origins of the unconventional regioselectivity during the cycloaddition steps was systematically investigated using density functional theory (DFT) calculations, unveiling the key features which control this reactivity, namely face-to-face $(\pi \ldots \pi)$ or edge-to-face $(C-H . . . \pi)$ interactions, primary orbital interactions and distortion from coplanarity in the transition structures (TSs) of the transformation. From the library of 24 derivatives synthesized, a pyridyl containing derivative displayed reversible, redshifted, $\mathrm{pH}$ triggered chiroptical switching properties, with CPL-sign reversal. It is found that protonation of the helicene causes a change of the angle between the electric and magnetic dipole moments related to the $S_{1} \rightarrow S_{0}$ transition, resulting in this rare case of reversible CPL sign inversion upon application of an external stimulus.
\end{abstract}

\section{Introduction}

Helicenes are extended $\pi$-conjugated structures consisting of ortho-fused aromatic rings. ${ }^{1,2}$ The repulsion between the terminal aromatic cycles forces the global framework to take an helical shape around a stereogenic axis. ${ }^{3}$ This chirality results in remarkable chiroptical properties, which are translated into different behaviors between the left- and right-handed optical rotation responses in their ground and excited states (electronic circular dichroism (ECD) and circularly polarized luminescence ( $C P L)$ ). Much synthetic efforts were undertaken to tune the helicene's (chir)-optical properties via extended conjugation, addition of heteroatoms and coordination to transition metals. ${ }^{4}$ Due to their potential for the development of optoelectronic devices, helicenes have generated a growing interest in the scientific community. For exemple, helicenes are promising scaffolds for the development of chiroptical switches resulting from the interconversion of two bistable chiral forms from external stimuli. ${ }^{5}$ Such stimuli-responsive chiral photoluminescent materials can be potentially used in anti-counterfeiting systems or to design molecular logic gates. For such application, the modulation of the output signal (emission wavelengths, CD/CPL intensity, etc.) in response to the stimulus ( $\mathrm{pH}$, redox potential, light, etc.) should be as large as possible in terms of intensity or sign difference. ${ }^{6}$ 


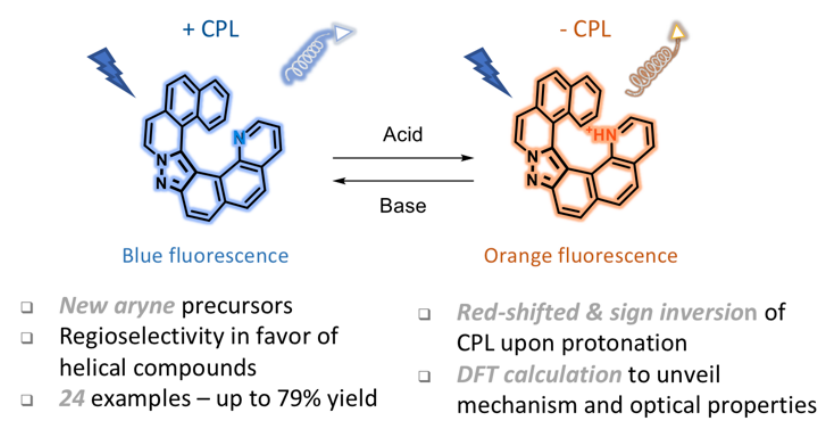

Figure 1. Synthesis and caracterization of heterohelicenes displaying chiroptical switch.

To unlock the potential of such chiral polycyclic aromatic hydrocarbons (PAH) in terms of application, the development of versatile synthetic avenues to obtain broad ranges of helicenes (including extended, heteroaromatic, substituted, symmetrical and unsymmetrical derivatives) is a milestone. Heteroaromatic helicenes have been generated via oxidative annulating reaction, ${ }^{7} \mathrm{C}-\mathrm{H}$ activation, ${ }^{8}$ radical reaction, ${ }^{9}$ cycloisomerisation of alkyne, ${ }^{10}$ intramolecular $\mathrm{NH} / \mathrm{CH}$ oxidative coupling, ${ }^{6 \mathrm{~d}, 11}$ and $[2+2+2]$-cycloadditions..$^{12}$ Despite the large array of procedures, the versatility of each approach remains partially limited and often the diversity has to be installed early in the synthesis.

Recently, we reported preliminary findings on a novel synthetic approach to helicenes through [3+2]cycloadditions between 3,4-phenanthryne and mesoionic sydnones. ${ }^{13}$ This methodology, which allows to construct unreported helical pyrazole derivatives, proceeds with an unexpected selectivity towards the helical C-shape product, over the less sterically hindered S-shape regioisomer. Such a selectivity is not commonly invoked in strain-promoted mesoionic cycloadditions. On the contrary, the majority of reports highlight that sydnones are challenging dipoles and are poorly regioselective. ${ }^{14,15}$ Herein, we provide a full account on our efforts resulting in the development of pyrazole-containing helicenes, including the design of new poly-heteroaromatic sydnones and arynes precursors,. The selectivity was fully investigated by DFT calculations, thus providing a comprehensive mechanistic picture. By means of this strategy, we could access a pH triggered chiroptical switch displaying CPL-sign reversal depending on the protonation state (Figure 1).

\section{Results and Discussion}

\section{Synthesis of polycyclic sydnone and aryne precursors and study of the cycloaddition}

To prove the versatility of this cycloaddition-based approach and the diversity of accessible structures, we aimed to increase the complexity of both the sydnone and the aryne precursors. We used the optimized palladium-catalyzed coupling reaction (see $\mathrm{SI}$ ) to prepare the substituted pre-helical mesoionic compounds. The use of $\mathrm{Pd}(\mathrm{OAc})_{2}(10 \mathrm{~mol} \%), \mathrm{PPh}_{3}\left(20\right.$ mol\%), an excess of $\mathrm{K}_{2} \mathrm{CO}_{3}$ (4 equiv) in DMF with $\mathrm{N}$-methylsydnone and 2-halobenzaldehyde derivatives as partner smoothly afforded the triand tetra-cyclic sydnones (Scheme 1).

Both coupling partners were easily accessible: the $N$-benzyl sydnone was obtained in $72 \%$ yield following the procedure of Shi and co-workers ${ }^{14 a}$ and the $\mathrm{N}$-methyl sydnone was obtained starting from the commercially available sarcosine in $31 \%$ yield, in one step. The aldehydes were obtained either from commercial sources, by reduction of the corresponding ester or ortho- $\mathrm{C}\left(\mathrm{sp}^{2}\right)-\mathrm{H}$ bromination of benzaldehydes according to the procedure described by Yu and co-workers. ${ }^{16}$ 
The reaction does not require anhydrous or degassed solvent to afford 1a-q in $11 \%$ to $91 \%$ yield. Sydnones bearing substituents (-Me and $-F$ ) in position 7 or 10 (1d, 1e, 1m) were obtained in 21 to $36 \%$ yields and the 8 -chlorosydnone $\mathbf{1 l}$ was obtained with $74 \%$ yield. In general, this methodology tolerates halides, alkyl, and electron-donating group, whereas degradation was observed for 2bromobenzaldehydes bearing an electron withdrawing group with attractive mesomeric effect (nitrile and nitro group) or the more reactive methylthiophene. Finally, heteroaromatic derivatives $\mathbf{1} \mathbf{p}$ and $\mathbf{1} \mathbf{q}$ could be isolated in 21 and $54 \%$ yields, respectively. As such, this methodology is complementary to the existing one to provide access to substituted poly-aromatic sydnones. ${ }^{17}$

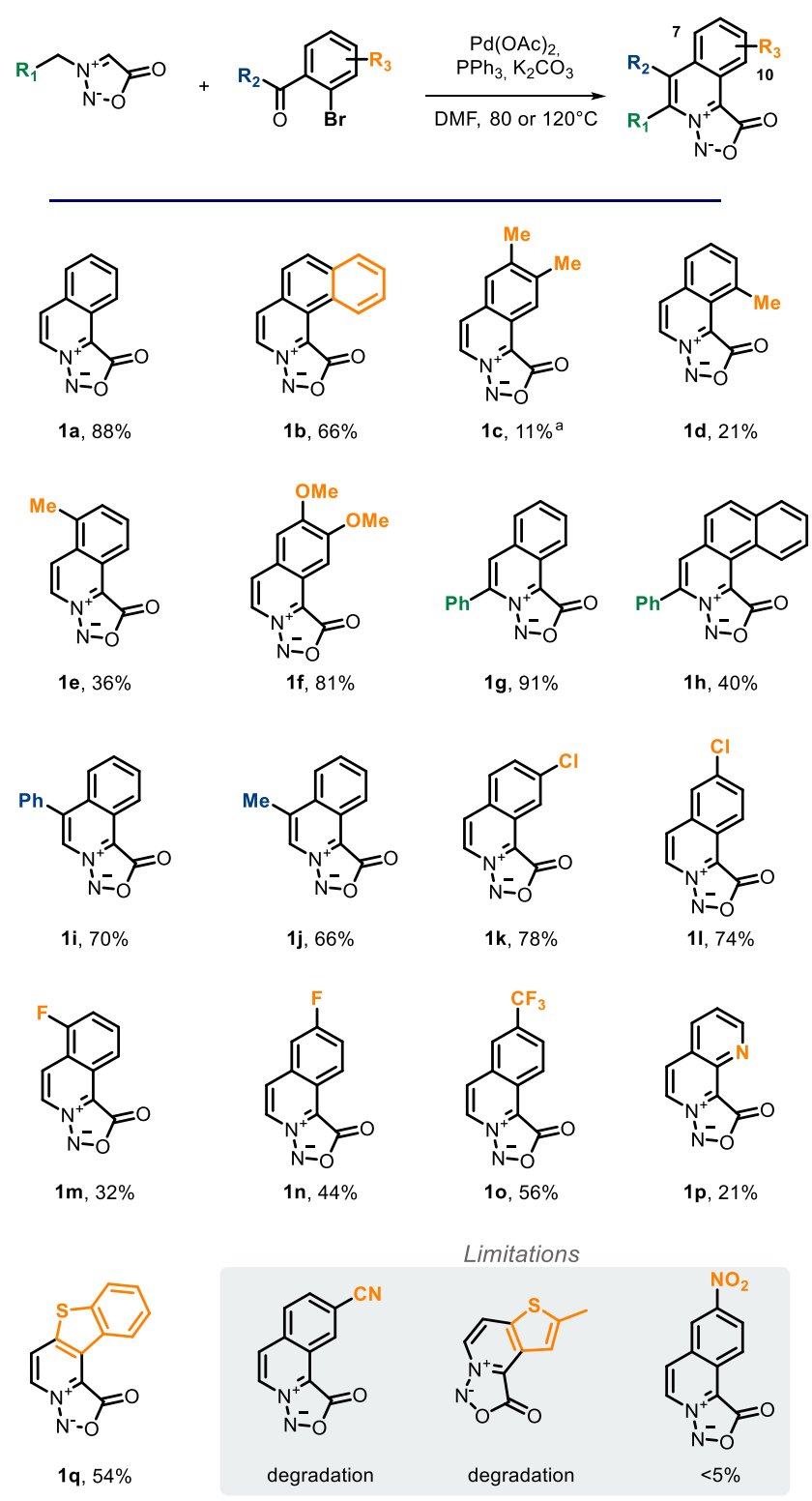

Scheme 1. Sydnones preparation. ${ }^{\text {a }}$ starting from the corresponding 2 -iodobenzaldehyde substrate.

With a library of 17 polycyclic sydnones in hand, we next focused our attention on the preparation of 3,4-phenanthryne derivatives. While structural diversity can be rapidly obtained on the mesoionic partner, the described synthetic access to this polycyclic aryne has so far been a limitation. 3,4phenanthryne is generated in situ from the silyl triflate precursor $9 a$, which is the most common and safe methodology to generate aryne systems. ${ }^{18}$ In 2000, Peña et al. described the access to 3,4- 
phenanthryne and other aryne precursors. ${ }^{19}$ Their pathway involved the cycloaddition between furan and 1,2-naphthyne, generated in situ from 1-bromonaphtyl-2-triflate with $n B$ BuLi, followed by an acidic treatment leading to a mixture of desired phenanthrene-4-ol 6a and phenanthrene-1-ol in variable ratios, which in our hands varied depending on the reaction scale. While convenient for their purpose, we decided to prepare the key phenanthrene-4-ol $\mathbf{6 a}$ in a scalable and selective manner following an alternative pathway. In addition, our strategy was adapted to access the $\pi$-extended analogue 1,2benzophenanthryne derivative, which is so far unreported (Scheme 2a). Starting from the commercially available 1-iodo-2-bromobenzene and 1-bromonaphtyl-2-triflate, a sequence of robust Sonogashira and Suzuki cross-couplings afforded the $2, \mathbf{2}^{\prime}$-diphenyl derivatives $\mathbf{3 a}$ and $\mathbf{3 b}$ in $\mathbf{9 0 \%}$ and $40 \%$ yield, over two steps. ${ }^{20}$ Deprotection of the silyl groups with TBAF $\mathrm{H}_{2} \mathrm{O}$ followed by Pt-catalyzed cyclisation, according to the procedure reported by Fürstner, provided the ortho-fused polyaromatic compounds $\mathbf{5 a}$ and $\mathbf{5 b}$, in $64 \%$ and $45 \%$ yields. ${ }^{21}$ Demethylation using $\mathrm{BBr}_{3}$, ortho-bromation with NBS and protection of the phenol with HMDS gave the precursors $\mathbf{8 a}$ and $\mathbf{8} \mathbf{b}$ for the final retro-Brook reaction. Finally, after treatment with $n \mathrm{BuLi}$ at $-78{ }^{\circ} \mathrm{C}$ followed by trapping with triflic anhydride, the aryne precursors were obtained in $64 \%$ and $23 \%$ yields, respectively. The overall yields for the $3,4-$ phenanthryne $9 a$ and 1,2-benzophenanthryne precursors $9 b$ were of $27 \%$ and $5 \%$, over 8 steps. The current synthesis provides a number of advantages over previous procedures, as it is scalable, does not require a cumbersome separation of regioisomers and can be easily adapted to access a library of derivatives. ${ }^{21,22}$ In fact, the Pt-catalyzed cyclisation has been reported on a series of derivatives bearing multiple substitution (methyl, methoxy or phenyl) or even with heterocycles (thiophene, pyrrole) and ferrocenyl. If required, substitutions might be easily implemented to this strategy thus allowing to insert additional diversity.

Pyridine-containing helicenes have shown interesting optical properties and have been utilized as ancillary ligand with transition metal complexes and as catalyst for asymmetric transformations. ${ }^{6 a, 6 b, 23}$ The design of 9,10-benzoquinolyne precursors, such as $\mathbf{1 3 a}$ and $\mathbf{1 3 b}$, would allow increasing the level of complexity of the heteroaromatic helicenes, as well as, provide insightful mechanistic understanding on the key cycloaddition step. Indeed, the presence of a nitrogen atom within the structure of the aryne might prevent the $\mathrm{C}-\mathrm{H} . . . \pi$ interaction, which is a key feature governing the regioselectivity of the process. We reasoned that the desired aryne precursors could be obtained starting from the commercially available benzo[h]quinoline. At first, a Pd-catalyzed $\mathrm{C}-\mathrm{H}$ activation reaction allowed the introduction of a hydroxyl group in position $\mathrm{C} 10 .{ }^{24}$ The bromination of compound $\mathbf{1 0}$ turned out to be quite challenging in terms of selectivity, despite extensive optimization using a variety of electrophilic brominating agents (see SI page S18). The utilization of NBS afforded a 1:1 separable mixture of the ortho and para-halogenated isomers $\mathbf{1 1 a}$ and $\mathbf{1 1} \mathbf{b}$. In order to take advantage of this side product, 11b was engaged in a Suzuki coupling reaction to afford 11c. Treatment with NBS provided 11d in a good yield of $47 \%$ over two steps. The phenols were next protected with a silyl group using the electrophilic reagent BSTFA. ${ }^{25}$ Due to their moderate stability, $\mathbf{1 2 a}$ and $\mathbf{1 2 b}$ were directly engaged in the retro-Brook rearrangement to afford benzoquinolyne precursors $13 \mathrm{a}$ and $\mathbf{1 3 b}$ in $51 \%$ and $24 \%$ yields, respectively over the last two steps. These pyridine heteroaromatic aryne precursors are so far unreported, and will be of interest in aryne cycloaddition chemistry and material science.

The reactivity of the sydnones $\mathbf{1 a - q}$ and silyltriflate polyaromatic derivatives $\mathbf{9 a}, \mathbf{9 b}, \mathbf{1 3 a}$ and $\mathbf{1 3 b}$ was then evaluated (Scheme 3). 
- Phenanthryne \& Benzophenanthryne precursors

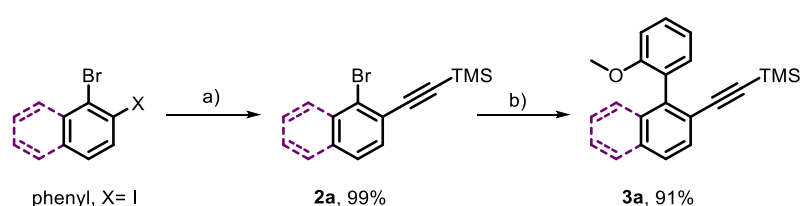

$\begin{array}{ccc}\text { phenyl, } X=1 & \text { 2a, } 99 \% & \text { 3a, } 91 \% \\ \text { naphtyl, } X=\text { OTf } & \text { 2b, } 59 \% & \text { 3b, } 95 \%\end{array}$

$\downarrow$ c), d)

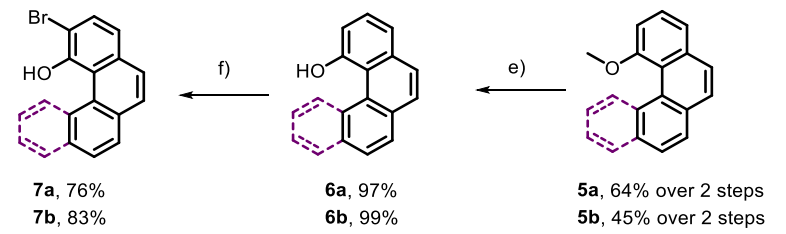

g)

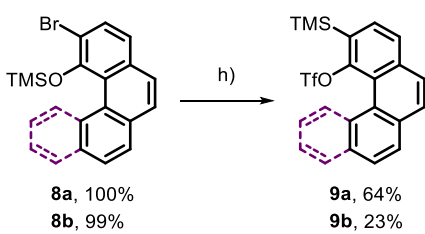

- Benzoquinolyne precursors
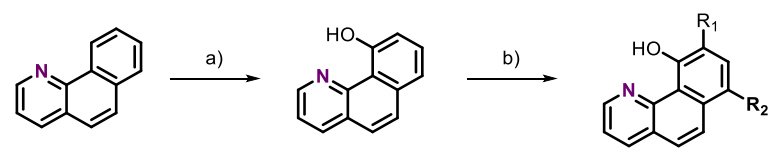

$10,79 \%$

11a, $\mathrm{R}_{1}=\mathrm{Br}, \mathrm{R}_{2}=\mathrm{H}, 32 \%$

c)

11b, $\mathrm{R}_{1}=\mathrm{H}, \mathrm{R}_{2}=\mathrm{Br}, 27 \%$

d) $\longrightarrow 11 \mathrm{c}, \mathrm{R}_{1}=\mathrm{H}, \mathrm{R}_{2}=\mathrm{Ph}, 72 \%$

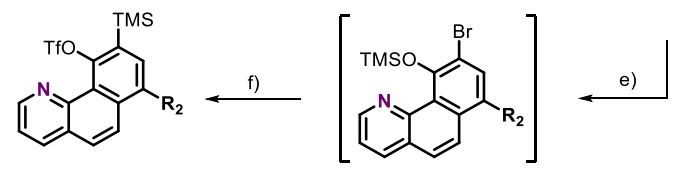

13a, $\mathrm{R}_{2}=\mathrm{H} 51 \%$ over 2 steps

13b, $\mathrm{R}_{2}=\mathrm{Ph} 24 \%$ over 2 steps

$12 a$

Scheme 2. Preparation of phenanthryne and benzophrenanthryne a) TMS-acetylene, $\mathrm{Pd}\left(\mathrm{PPh}_{3}\right)_{2} \mathrm{Cl}_{2}, \mathrm{Cul}, \mathrm{NEt}{ }_{3}, \mathrm{DMF}$, rt b) $\mathrm{Pd}_{2} \mathrm{dba}_{3}$, SPhos, $\mathrm{K}_{3} \mathrm{PO}_{4}, 2$-methoxyphenylboronic acid, Toluene, $80{ }^{\circ} \mathrm{C}, 8 \mathrm{~h} \mathrm{c}$ ) TBAF. $\left.\mathrm{H}_{2} \mathrm{O}, \mathrm{THF}, 0{ }^{\circ} \mathrm{C}, 3 \mathrm{~h} \mathrm{~d}\right) \mathrm{PtCl}_{2}$, Toluene, $80^{\circ} \mathrm{C}$, $20 \mathrm{~h}$ e) $\mathrm{BBr}_{3}, \mathrm{DCM},-78^{\circ} \mathrm{C}$ to rt, overnight f) NBS, ACN, $0{ }^{\circ} \mathrm{C}$ to rt, $\left.2 \mathrm{~h} \mathrm{~g}\right) \mathrm{HMDS}, \mathrm{THF}$, reflux, $5 \mathrm{~h} \mathrm{~h}$ ) $n \mathrm{BuLi}, \mathrm{THF},-78^{\circ} \mathrm{C}, 30 \mathrm{~min}$ then $\mathrm{Tf}_{2} \mathrm{O}, \mathrm{Et}_{2} \mathrm{O},-78{ }^{\circ} \mathrm{C}, 40 \mathrm{~min}$; for the preparation of benzoquinolyne precursors: a) $\mathrm{Pd}(\mathrm{OAC})_{2}, \mathrm{Phl}(\mathrm{OAC})_{2}, \mathrm{ACN}, 100{ }^{\circ} \mathrm{C}, 24 \mathrm{~h}$ then $\mathrm{NaOH}, \mathrm{MeOH}, \mathrm{rt}, 3 \mathrm{~h} \mathrm{~b}) \mathrm{NBS}, \mathrm{DCM}, 0{ }^{\circ} \mathrm{C}, 1 \mathrm{~h}$ c) phenyl boronic acid, $\mathrm{Pd}_{2} \mathrm{dba}_{3}$, SPhos, $\mathrm{K}_{3} \mathrm{PO}_{4}$, toluene, $100{ }^{\circ} \mathrm{C}, 8 \mathrm{~h}$ d) $\mathrm{NBS}$, ACN, $1 \mathrm{H}$ e) BSTFA, ACN, $60{ }^{\circ} \mathrm{C}, 1.5 \mathrm{~h}$ f) $n \mathrm{BuLi}, \mathrm{THF},-78^{\circ} \mathrm{C}, 30 \mathrm{~min}$ then $\mathrm{Tf}_{2} \mathrm{O},-78^{\circ} \mathrm{C}, 40 \mathrm{~min}$.

The 1,3-dipolar cycloaddition occurred in the presence of TBAF (1.25 equiv) as fluoride source in THF. It is noteworthy that the regioselectivity in favor of the most strained compound was maintained without any influence of the temperature or solvent used. 
A)
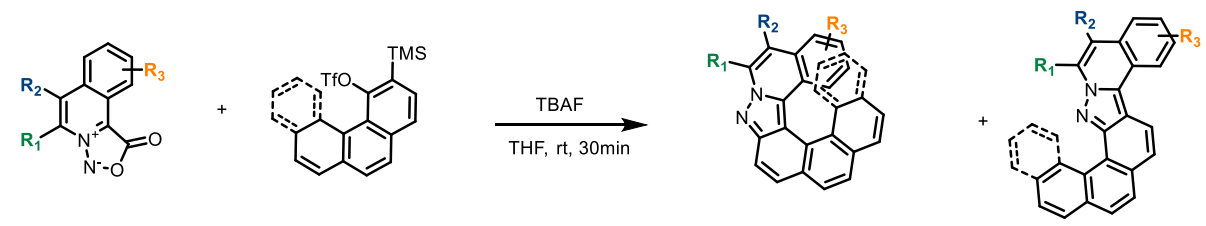

- (Un)Substituted heterohelicenes

C-shape (major isomer)
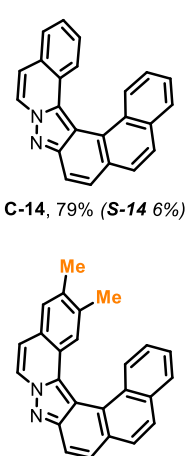

C-19, 49\% (S-19, 3\%)

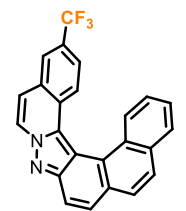

C-24, $70 \%(S-24,11 \%)$

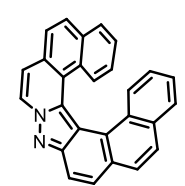

C-15, 62\% (S-15 4\%)

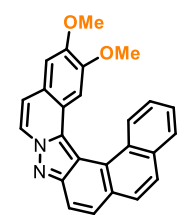

C-20, $18 \%$ (S-20, 2\%)

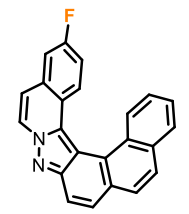

C-25, 53\% (S-25, 6\%)

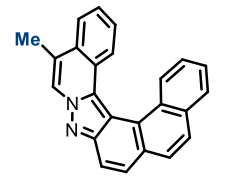

C-16, $60 \%$ (S-16 6\%)

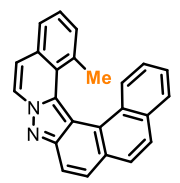

C-21, 34\% (S-21, n.d.)

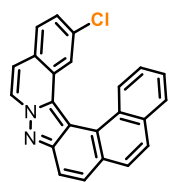

C-26, $73 \%($ S-26, $8 \%)$

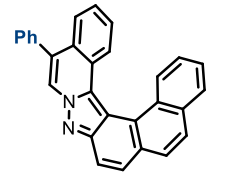

C-17, 76\% (s-17 n.d.)

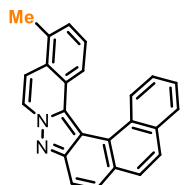

C-22, 37\% (S-22, n.d.)

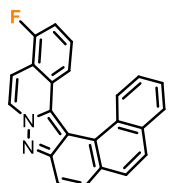

C-27, $50 \%(S-27,7 \%)$

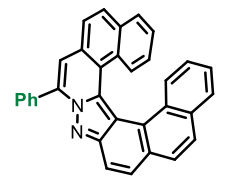

C-18, 30\% (S-18 9\%)

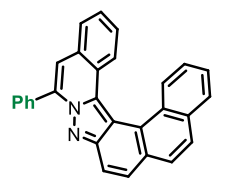

C-23, $73 \%$ (S-23 10\%)

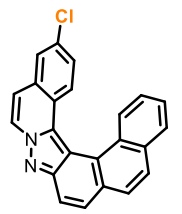

C-28, $65 \%(S-28,8 \%)$

- Polyheteroaromatic helicenes
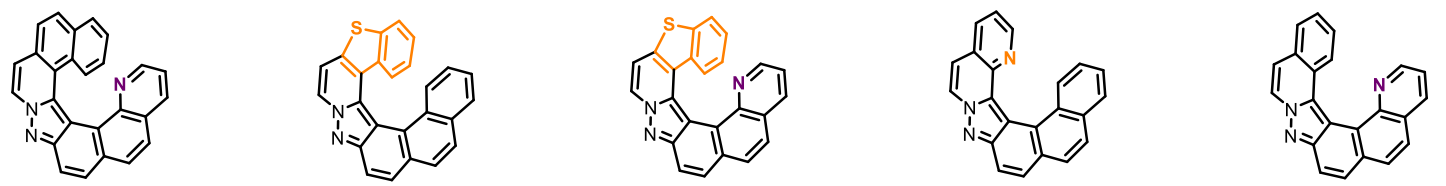

C-29, $52 \%$ (S-29, n.d.)

C-30, $35 \%$ (S-30, n.d.)
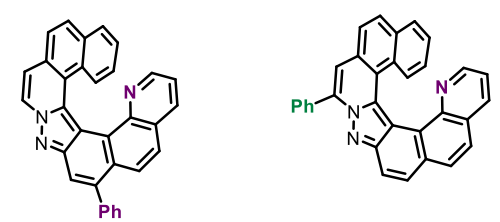

C-34, $45 \%$ (S-34, n.d.)

C-35, $41 \%$ (S-35, n.d.)

C-31, 41\% (S-31, n.d.)

C-32, 26\% (S-32, n.d.)

C-33, 38\% (S-33, n.d.) - Extended $\pi$-conjugation

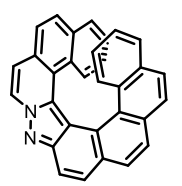

B) Crystallographic data
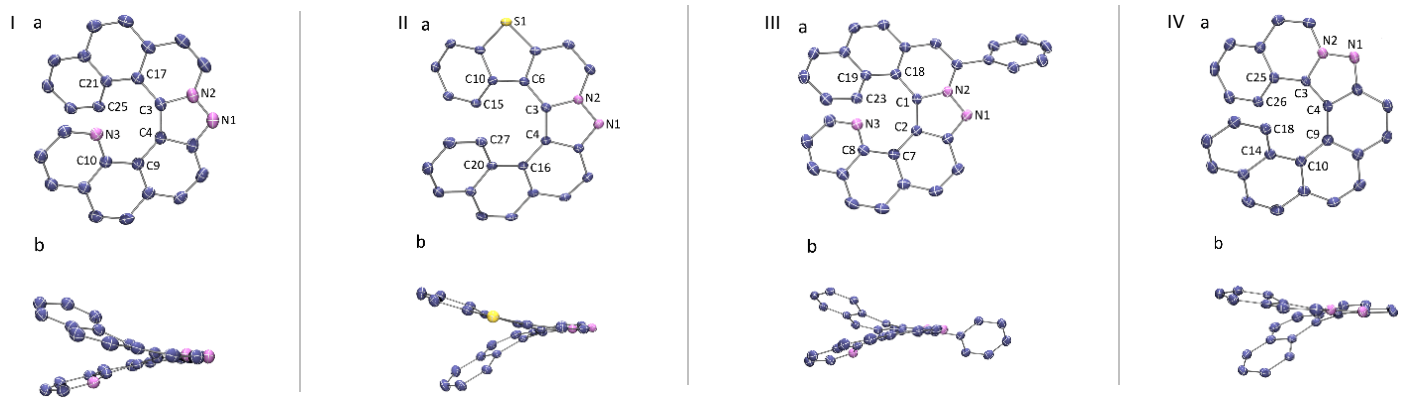

Scheme 2. Scheme 3. A) Only C-shape compounds are represented here when possible the yield of isolated S-shape is given in bracket. n.d. not determined. B) Crystallographic data for C-29 (I), C-30 (II), C-35 (III) and C-36 (VI); a: top view; b: side view. See SI for dihedral angles, for C-29 C-30 C-35 C-36). 
Reactions between sydnones $\mathbf{1 d}, \mathbf{1 e}, \mathbf{1} \mathbf{m}, \mathbf{1}$ and $\mathbf{1 q}$ with the 3,4-phenanthryne afforded the helicenes C-21, C-22, C-27, C-28, C-30, C-32 with moderate to good yields from $26 \%$ to $65 \%$. Single crystals of C30 suitable for crystallographic analysis were obtained by slow evaporation of a chloroform solution and allowed to confirm the helical structure with both pyrazole and thiophene heterocycles (see SI for crystal structures). We then subjected 1,2-benzophenanthryne precursor $9 \mathbf{b}$ to our protocol with sydnones $\mathbf{1 a}$ and $\mathbf{1 b}$. [7]-azahelicene $\mathbf{C}-\mathbf{3 6}$ and [8]-azahelicene $\mathbf{C}-\mathbf{3 7}$ were isolated in $\mathbf{3 7 \%}$ and $\mathbf{3 1 \%}$ yield, respectively. Slow evaporation of a chloroform solution yielded crystals of C-36 suitable for singlecrystal X-ray diffraction, thus unequivocally confirming its structure (Scheme 3B, III). The reactivity of 9,10-benzoquinolyne $13 \mathbf{a}$ and $\mathbf{1 3} \mathbf{b}$ precursors were next investigated. To our delight, the reaction proceeded smoothly with sydnones $\mathbf{1 a}, \mathbf{1} \mathbf{b}, \mathbf{1} \mathbf{g}$, and $\mathbf{1 q}$ and afforded the corresponding helicenes $\mathbf{C - 2 9}$, C-31, C-33, C-34 and C-35 with yields ranging from 38 to 52\%. Crystals of C-29 and C-35 were obtained by slow diffusion of hexanes in dichloromethane. The crystal structures of compounds C-29, C-30, C35 and C-36 are shown in Figures 3B.

With 9a as coupling partner, a ratio of at least 9:1 in ${ }^{1} \mathrm{H} \mathrm{NMR}$ of the C-shape versus the S-shape product was observed. To our surprise, no S-shape product could be detected by TLC, NMR or LC-MS when using aryne precursors $\mathbf{9 b}, \mathbf{1 3 a}$ and $\mathbf{1 3 b}$ as dipolarophiles.

\section{Understanding the origins of the regioselectivity of the cycloaddition by DFT calculations}

In our previous report, we identified stabilizing C-H..pi interactions in the key TS leading to C-14 as the main factor explaining the outstanding regioselectivity of the reaction. However, these findings do not totally explain the results with our new substrates exhibiting different structural features, especially for pyridine-containing ones. Thus, we computed the free energy surfaces of the five sydnone/aryne systems leading to $\mathbf{C}-\mathbf{2 9}, \mathbf{C}-\mathbf{3 2}, \mathbf{C}-\mathbf{3 3}, \mathbf{C}-\mathbf{3 6}$ and $\mathbf{C}-\mathbf{3 7}$ (optimizations and single points energy refinements at the M06-2X/6-31+G(d,p) and M06-2X/6-311+G(2d,2p) levels of theory, respectively). The energy profile of the representative reaction of the sydnone $1 \mathrm{a}$ and the pyridine-containing aryne $\mathbf{3 8} \mathrm{c}$ is shown in Figure 2A. The other profiles can be found in SI (pages S43-S46).

Selectivity between the helical and linear products in these reactions is determined at the 1,3-dipolar cycloaddition step. Indeed, this cycloaddition occurs with a relatively low activation barrier (10.4-15.9 $\mathrm{kcal} / \mathrm{mol}$, TS1, Figure 2A), irreversibly forming the corresponding cycloadducts (int1) with $\Delta$ Gs between -27 and $-42 \mathrm{kcal} / \mathrm{mol}$. Subsequent inversion of the $\mathrm{N} 3$ nitrogen $(3.4-6.4 \mathrm{kcal} / \mathrm{mol}, \mathrm{TS} 2)$ aligns the nitrogen lone pair in the required antiperiplanar orientation to expel the carbon dioxide molecule, which occurs from the metastable species int 2 and forms the corresponding retro-cycloaddition pyrazole products in a highly exergonic process ( $\Delta \mathrm{Gs}$ between -130 and $-140 \mathrm{kcal} / \mathrm{mol}$ ). ${ }^{26}$ Of note, the computed structures of the helical products C-29 and C-36 mimic the crystallographic structures, with similar dihedral angles along the helicene backbone (differences between -1.1 and $2.2^{\circ}$, see SI Figure S18). For all the studied systems, the differences of activation free energies calculated between the TSs leading to the two regioisomers are above $1.4 \mathrm{kcal} / \mathrm{mol}$ (9:1 theoretical ratio between the $\mathrm{C}$ - and $\mathrm{S}$-shape products at room temperature), in agreement with the almost exclusive formation of helical products observed experimentally.

From the transition structures of the five studied systems, we first examined the contribution of aromatic interactions in lowering the activation barrier in favor of the pro-helical TS. In route to the helicene product, the arrangement of the two reaction partners puts their respective polycyclic backbones in close proximity, and the development of stabilizing aromatic-aromatic interactions was 
previously identified as a key factor in the origin of selectivity for example for C-14. ${ }^{13}$ To quantify this stabilization, we estimated the binding energies $\Delta \mathrm{E}_{\text {int,ar }}$ between the aromatic moieties in the transition structures (see $\mathrm{SI}$, page $\mathrm{S} 49$ for details), which result from $\pi$-stacking forces such as face-to-face $(\pi \ldots \pi)$ or edge-to-face $(\mathrm{C}-\mathrm{H} . . . \pi)$ interactions. ${ }^{27}$ The computed values of $\Delta \mathrm{E}_{\text {int,ar }}$ (Figure $2 \mathrm{~B}$ ) confirm the stabilization offered by edge-to-face interactions in TS1 C-14 $\left(\Delta \mathrm{E}_{\text {int,ar }}=-0.8 \mathrm{kcal} / \mathrm{mol}\right)$, TS1 C-29 $\left(\Delta \mathrm{E}_{\text {int,ar }}\right.$ $=-1.3 \mathrm{kcal} / \mathrm{mol})$ and TS1 C-36 $\left(\Delta \mathrm{E}_{\text {int,ar }}=-1.9 \mathrm{kcal} / \mathrm{mol}\right)$, as well as face-to-face interactions in TS1 C-37 $\left(\Delta \mathrm{E}_{\text {int,ar }}=-3.3 \mathrm{kcal} / \mathrm{mol}\right)$. The systems with the greater aromatic stabilization also enjoy greater free energy gaps between the regioisomeric TSs, showcasing the importance of these interactions for selectivity (Figure 2.B I-IV). Of note, there is a large difference in $\Delta \mathrm{E}_{\text {int,ar }}$ going from the TS leading to the [7]-helicene (TS1 C-36) to the one for the [8]-helicene (TS1 C-37). With the latter, face-to-face parallel $\pi-\pi$ interactions become possible, which strongly increase the stabilization afforded. It is likely that TSs leading to even longer helicenes could benefit from even greater interactions than those identified here. TS1 C-32 (Figure 2.B VI) also benefits from stabilizing interactions between the aromatic moieties of the reactants, as the binding interaction energy is calculated at $-1.0 \mathrm{kcal} / \mathrm{mol}$. The origin of this stabilization is not as obvious as the $\pi$-stacking observed in the previous transition structures, but likely arises from electrostatic interactions between the nitrogen lone pair from the sydnone quinoline backbone and the electropositive aromatic hydrogens in close proximity (see SI pages S53-54 for charge distribution and non-covalent interactions analysis). In the case of TS1 C-33 (Figure 2.B V), the presence of the $\mathbf{3 8 c}$ pyridine-like nitrogen, in place of a $\mathrm{C}-\mathrm{H}$ prone to provide edgeto-face $\pi$-stacking with the sydnone (like in TS1 C-14), prevents similar stabilizing interactions. No binding energy is found for this system $\left(\Delta \mathrm{E}_{\text {int,ar }}=0.0 \mathrm{kcal} / \mathrm{mol}\right)$. However, our calculations predict a high selectivity $\left(\Delta \Delta \mathrm{G}^{*}=2.2 \mathrm{kcal} / \mathrm{mol}\right)$ in agreement with the experimental results, suggesting that a different factor controls the regioselectivity for this system.

We subsequently examined the frontier molecular orbitals (FMOs) of the reactants, as primary orbital interactions usually explain the regioselectivity of [3+2] cycloadditions. ${ }^{28}$ In all studied systems, the reaction is driven by interactions between the HOMO of the sydnone - with the biggest coefficient on the N2 atom (Figure 2.C I) - and the LUMO of the aryne (see SI pages S51-53 for more details). The LUMO coefficient on the aryne's external carbon - whose interaction with sydnone N2 leads to the helicene - is significantly larger than on the internal carbon for arynes $\mathbf{3 8 a}$ and $\mathbf{3 8 b}$, but not for $\mathbf{3 8 c}$ (Figure 2.C II). This analysis confirms the regioselectivity observed in reactions with $\mathbf{3 8 a}$ and $\mathbf{3 8 b}$ (C-14, C-36, C-37 and C-32), in addition to the stabilizing aromatic interactions, but does not explain why the reaction of $\mathbf{3 8} \mathbf{c}$ with $\mathbf{1 a}$ (leading to $\mathbf{C}-\mathbf{3 3}$ ) is selective as well. We then wondered whether the selectivity could be explained by the Houk-Garg model for addition on arynes, which is based on the internal angles on the aryne carbons and their changes at the TS. ${ }^{14 c}$ As seen in Table S5, this model could not explain the current results, neither could a distortion/interaction analysis on the TS1 structures. ${ }^{29}$

The high regioselectivities observed in the reactions of aryne $\mathbf{3 8 c}$ with sydnone $\mathbf{1 a}$ and $\mathbf{1 b}$ seem to arise from unfavorable distortions in the S-shape TS instead of favorable interactions in the pro-helical TS. Indeed, ideal primary orbital interactions in [4+2]-cycloadditions occur when all four bond-forming atoms are in a coplanar arrangement (dihedral angle of $0^{\circ}$ ). 
A) Potential energy surface

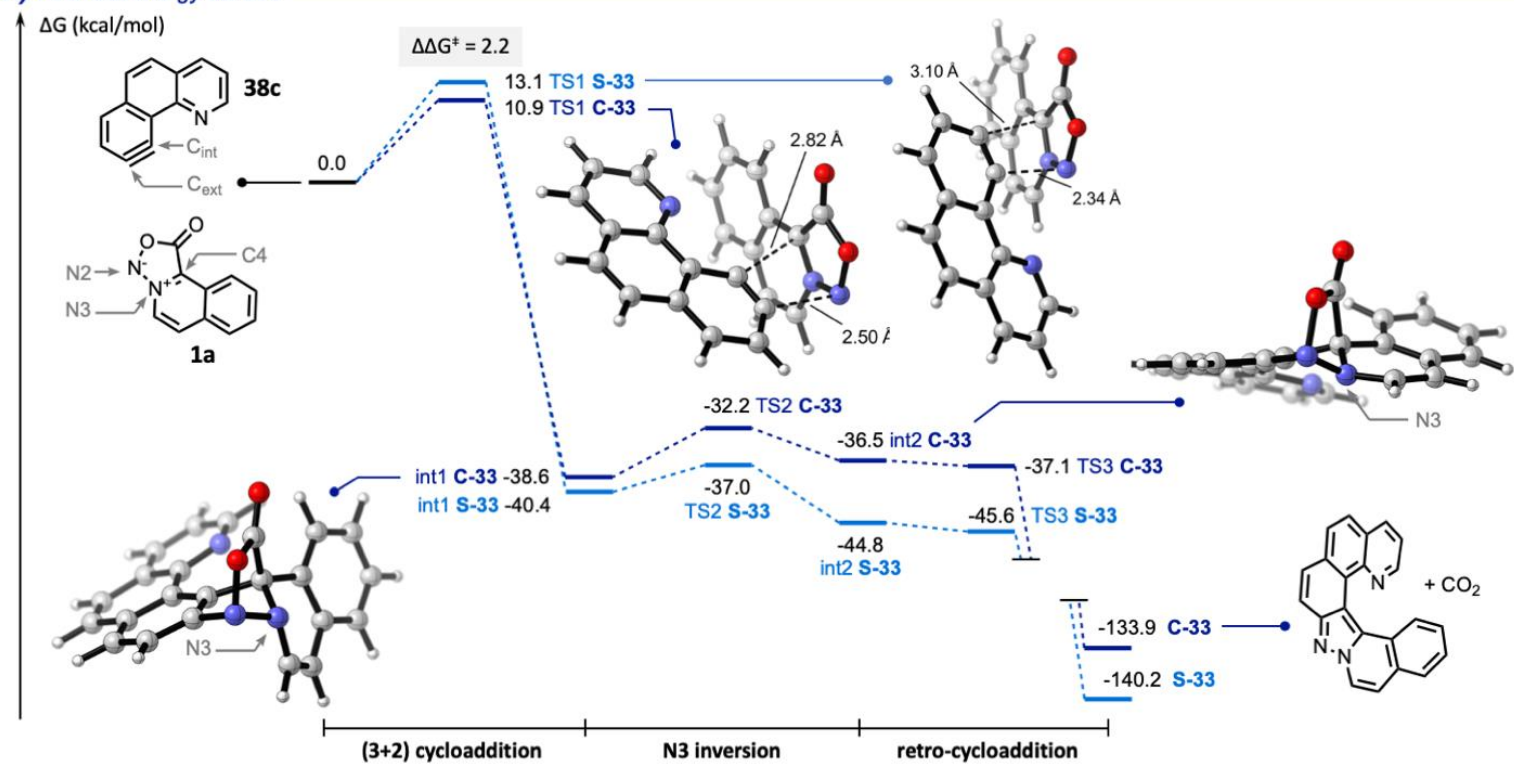

B) Transition structures
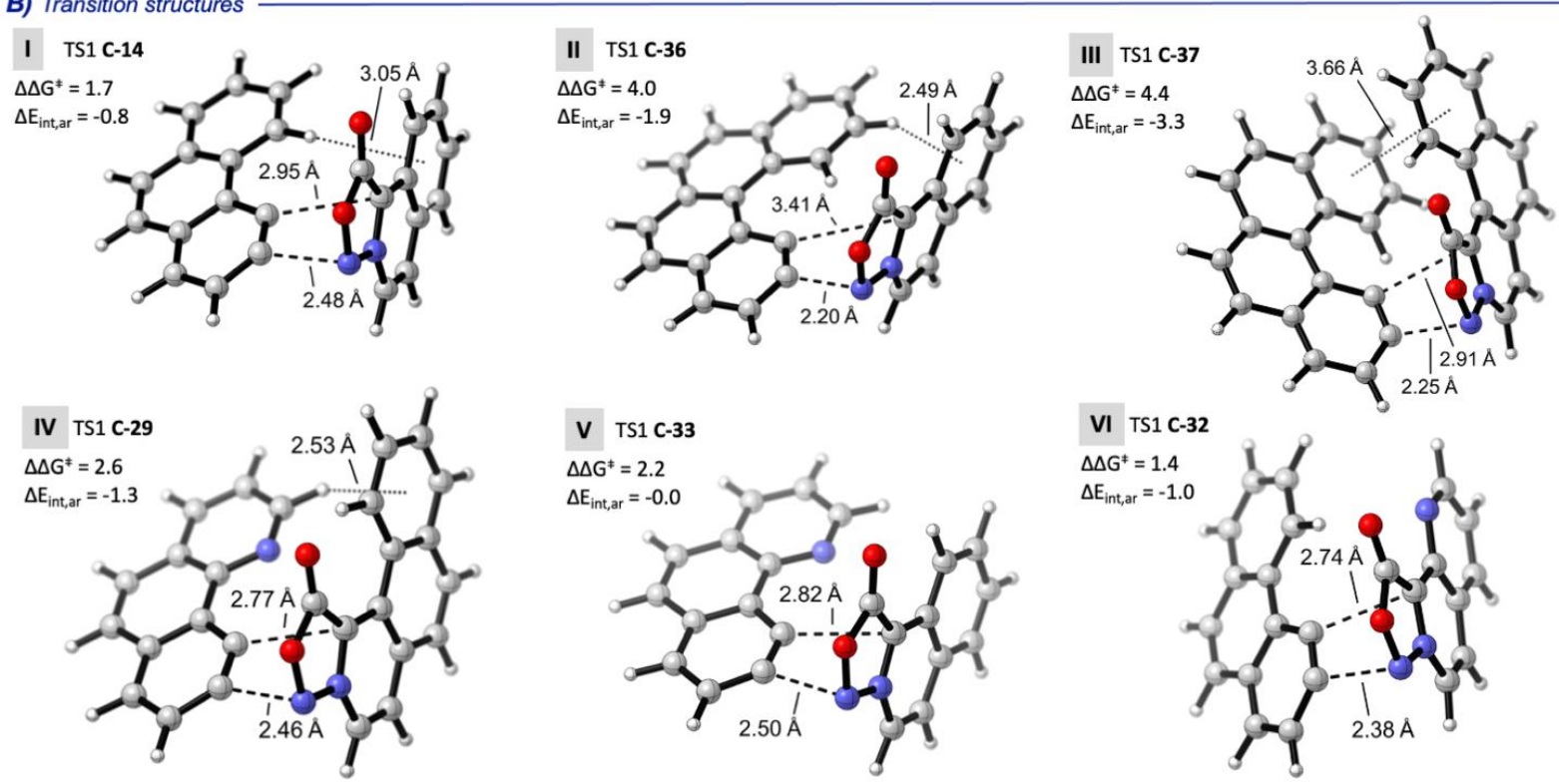

C) Frontier Molecular Orbitals

I Sydnone 1а номо

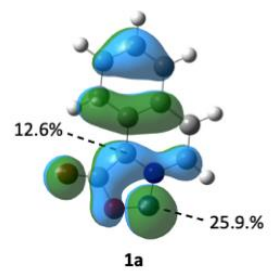

II Arynes LUMOs

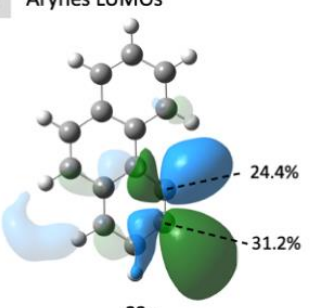

38a

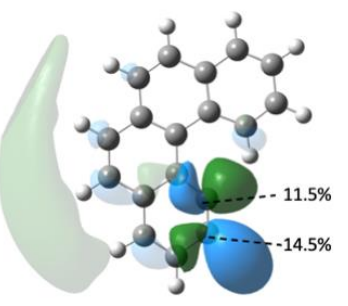

38b

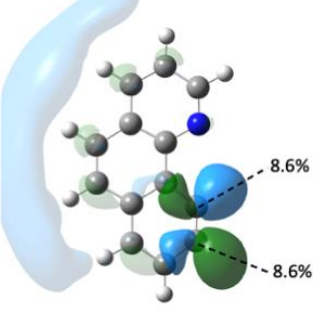

$38 \mathrm{c}$

Figure 2. All energy and free energy values are in $\mathrm{kcal} / \mathrm{mol}$ and were calculated at the M06-2X/6-311+G(2d,2p)/SMD(THF)// M06-2X/6-31+G(d,p) level of theory. A) Energy profile for the reaction of $1 \mathbf{a}$ with $\mathbf{3 8 b}$ to form C-33 and S-33. B) Optimized transition structures leading to the helical products, $\Delta \Delta \mathrm{G}^{*}=$ difference in activation free energy between the $\mathrm{S}$-shape and the pro-helical (C-shape) transition structures; $\Delta \mathrm{E}_{\text {int,ar }}=$ binding energies between the aromatic moieties of the reactants (see $\mathrm{SI}$ for details). C) Frontier Molecular Orbitals of selected compounds. Orbitals were computed at the HF/6-311+G(2d,2p) level of theory on the M06-2X-optimized geometries. Orbital coefficients were calculated by Hirshfeld method using the Multiwfn software. ${ }^{30}$ 

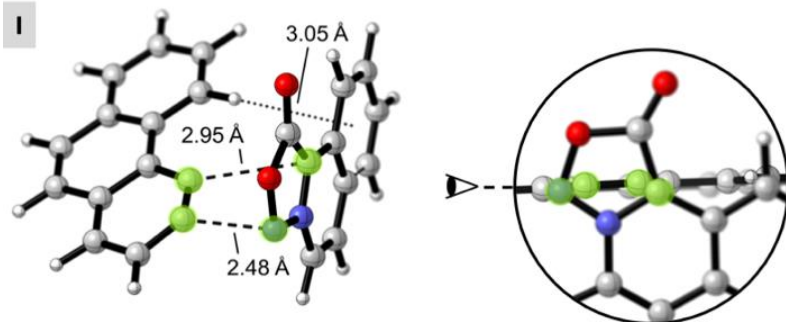

TS1 C-14
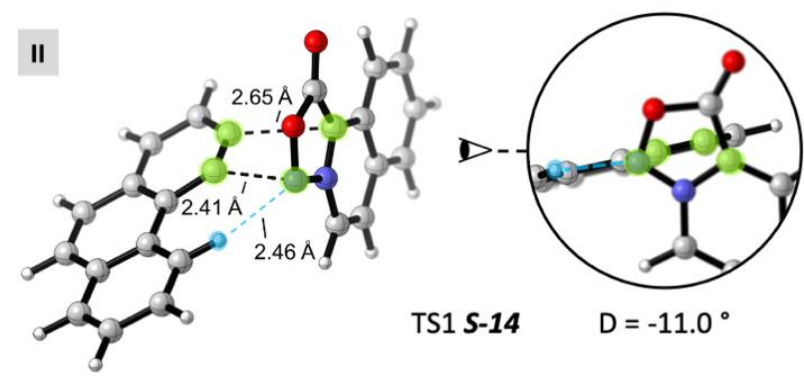
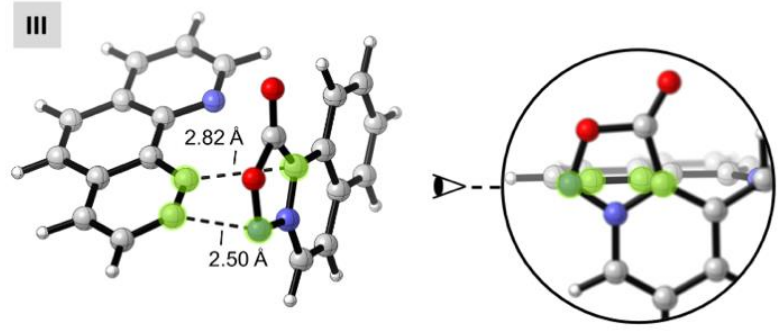

TS1 C-33

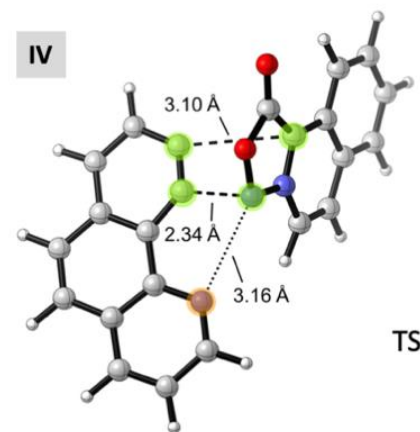

Figure 3. Optimized TS geometries leading to the C- and S- shape products of the reactions of aryne $\mathbf{3 8 a}$ and $\mathbf{3 8} \mathbf{c}$ with sydnone 1a. In green: the 4 bond-forming atoms. $\mathrm{D}=$ dihedral angle between the bond-forming atoms. In light blue: $\mathrm{H}$-bonding from the aryne backbone to the sydnone. In orange: pyridine-like nitrogen displaced to avoid interacting with the sydnone N2.

Transition structures computed with arynes $\mathbf{3 8 a}$ and $\mathbf{3 8 b}$ all present almost perfect coplanarity with dihedral angles between -1 to $-15^{\circ}$. The representative TSs forming C-14 and S-14 (1a + 38a) are shown in Figure 3, panels I and II. Of note, the slight misalignment in TS1 S-14 seems to be caused by favorable $\mathrm{H}$-bonding between $\mathrm{N} 2$ of the sydnone and an aromatic hydrogen (Figure $3 \mathrm{II}$, in blue).

However, in the case of aryne 38c, the TS leading to the S-shape regioisomer is significantly distorted from a planar arrangement (dihedral angle of $-34^{\circ}$ ), pushing the $\mathrm{C} 4-\mathrm{C}_{\text {ext }}$ distance to $3.1 \AA$ and leading to less efficient orbital overlap and a higher activation barrier (Figure 3 IV). This distortion, absent from TS1 C-33 (Figure $3 \mathrm{III}$ ), is likely due to the lone pairs from both the pyridine and the sydnone nitrogens, which would overlap if the TS were perfectly coplanar, resulting in significant electrostatic repulsion.

These results show that the regioselectivity observed in the polyaromatic sydnones 1,3-dipolar cycloadditions with arynes relies on two different factors, depending on the aryne partner used in the reaction. For arynes $\mathbf{3 8 a}$ and $\mathbf{3 8 b}$, their LUMO coefficients favor primary orbital interactions in the formation of the pro-helical TS. For reactions with aryne 38c, distortion of the S-shape TS raises the corresponding activation energy. In both scenarios, the development of stabilizing aromatic interactions, when possible, contributes to a yet higher energy gap between the two regioisomeric transition structures in favor of the helical product.

(Chir)optical properties of pyridine containing helicenes and their application to chiroptical switches

As pyridine containing heterohelicenes exhibit high proton affinity, we have considered them as potential candidates to develop efficient $\mathrm{pH}$ triggered chiroptical switches. ${ }^{6 b}$ First, we have studied in depth the (chir)optical properties of molecule $\mathbf{C}-\mathbf{2 9}$ and its protonated counterpart $\mathbf{C}-\mathbf{2} \mathbf{2} \bullet \mathbf{H}^{+}$. In order to rationalize optical and chiroptical properties of these molecules, we also performed time-dependent 
(TD) DFT calculations, to predict the absorption and emission spectra, at the B3LYP-D3(BJ)/6$311+\mathrm{G}(2 \mathrm{~d}, 2 \mathrm{p}) / \mathrm{IEF}-\mathrm{PCM}\left(\mathrm{CH}_{2} \mathrm{Cl}_{2}\right)$ level of theory (see $\mathrm{SI}$ for details). This method was chosen as it is known to provide accurate excited state geometries. ${ }^{31}$ The ground state $\left(\mathrm{S}_{0}\right)$ and first excited state $\left(\mathrm{S}_{1}\right)$ were optimized for each compound and the oscillator and rotatory strengths of their first 100 vertical transitions were obtained, then fitted to Gaussian functions with a half-width at half-height of $0.2 \mathrm{eV}$. The resulting predicted spectra, along with selected transitions, are shown in Figure 4 with the spectra measured experimentally. ${ }^{32}$

The photophysical properties of racemic mixture of $\mathbf{C}-29$ and $\mathbf{C}-29 \bullet \mathbf{H}^{+}$are shown in panels $\mathrm{A}$ and $\mathrm{B}$ of Figure 4, respectively. The $\mathrm{p} K_{\mathrm{a}}$ value of $\mathbf{C}-\mathbf{2 9} \bullet \mathrm{H}^{+}$was determined experimentally to be in the range of 3.8-4.0 (see SI page S39), thus $\mathbf{C}-\mathbf{2 9} \bullet \mathbf{H}^{+}$could be easily obtained by treating a solution of C-29 with TFA. In its basic form, the [7]-azahelicene displays a typical absorption spectrum, similar to the one we previously reported for $\mathbf{C}-\mathbf{1 5}$ (see SI page S33), with three strong bands centered at $236 \mathrm{~nm}(\varepsilon=43000$ $\left.\mathrm{M}^{-1} \mathrm{~cm}^{-1}\right), 263 \mathrm{~nm}\left(\varepsilon=27000 \mathrm{M}^{-1} \mathrm{~cm}^{-1}\right)$ and $307 \mathrm{~nm}\left(\varepsilon=20400 \mathrm{M}^{-1} \mathrm{~cm}^{-1}\right)$ (Figure 4A). From the TD-DFT results, we estimate these absorptions are due to the transitions between the $S_{0}$ and $S_{27}$ (oscillator strength $f=0.61), S_{22}(f=0.24)$ and $S_{8}(f=0.18)$ states, respectively. Other bands of lower intensity are also found at $350 \mathrm{~nm}\left(\varepsilon=12850 \mathrm{M}^{-1} \mathrm{~cm}^{-1}, \mathrm{~S}_{0} \rightarrow \mathrm{S}_{3}, \mathrm{f}=0.26\right), 402 \mathrm{~nm}\left(5391 \mathrm{M}^{-1} \mathrm{~cm}^{-1}\right)$ and $430 \mathrm{~nm}(5397$ $\mathrm{M}^{-1} \mathrm{~cm}^{-1}, \mathrm{~S}_{0} \rightarrow \mathrm{S}_{1}, \mathrm{f}=\mathbf{0 . 1 1}$ ). The absorbance spectrum of $\mathrm{C}-\mathbf{2 9} \bullet \mathrm{H}^{+}$, on the other hand, is expanded to longer wavelengths compared to C-29 (Figure 4B) and shows a new broad band centered around 450 $\mathrm{nm}\left(\varepsilon=2400 \mathrm{M}^{-1} \mathrm{~cm}^{-1}\right)$ which is determined by TD-DFT as the transition between its $S_{0}$ and $S_{1}$ states ( $f$ $=0.04)$.

Next, the two enantiomers of C-29 were successfully separated by chiral HPLC with an excellent enantiopurity (see SI, page S32) and independently protonated. The ECD spectra of both enantiomers of C-29 and $\mathbf{C}-29 \bullet \mathrm{H}^{+}$(Figure 4C and D) were then recorded in dichloromethane, and in both cases displayed a perfect mirror effect. 

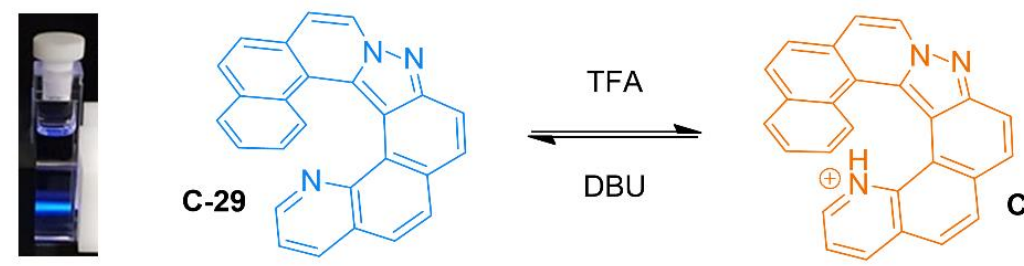

$\mathrm{C}-29 \cdot \mathrm{H}^{+}$

- Absorption
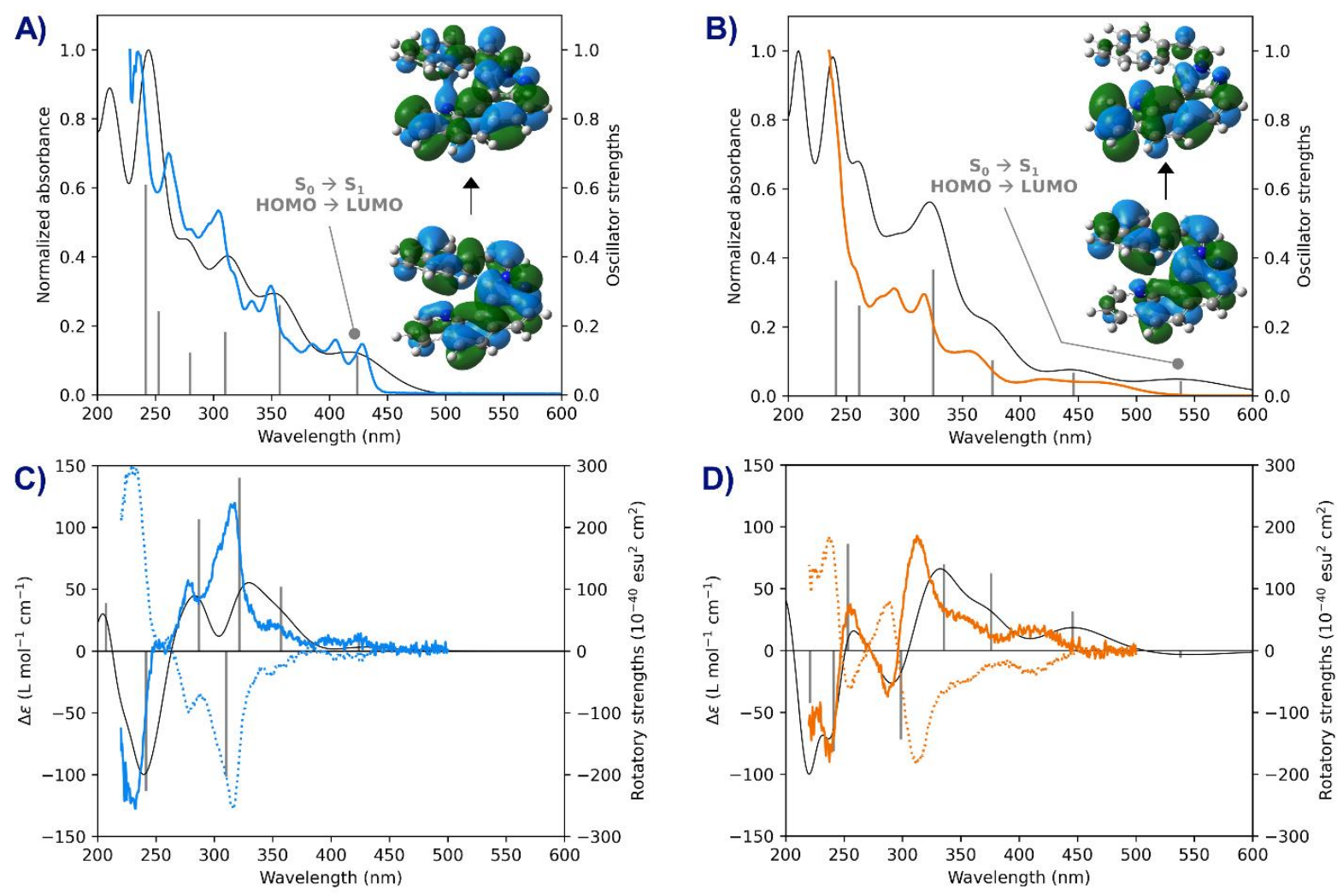

- Emission
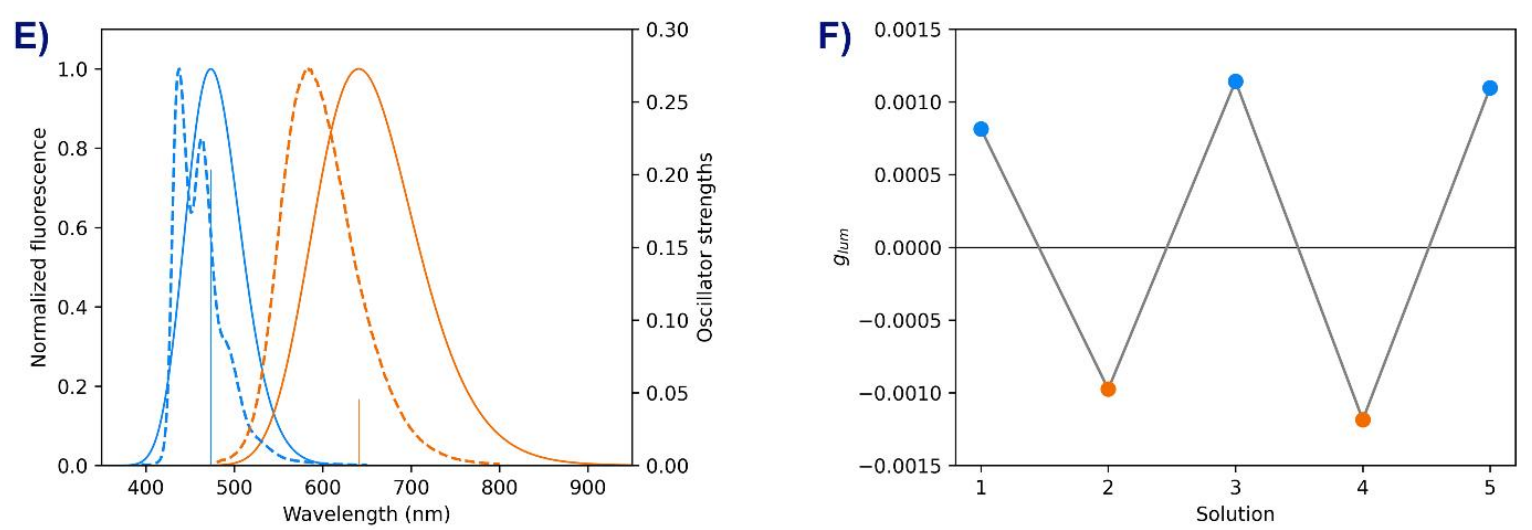

Figure 4: Experimental and computational spectra of $\mathbf{C}-29$ (blue) and $\mathbf{C}-\mathbf{2 9} \bullet \mathbf{H}^{+}$(orange). A) and B) Experimental absorption spectra (color) recorded in $\mathrm{CH}_{2} \mathrm{Cl}_{2}\left(\mathrm{C}=5 \times 10^{-5} \mathrm{M}\right)$, along with oscillator strengths for selected transitions (grey bars) and full predicted spectra (black curves) from TD-DFT calculations. NBOs for the HOMO and LUMO of each compound are shown as inset. C) and D) Experimental circular dichroism (CD) spectra for the (+)-enantiomer (full color) and (-)-enantiomer (dashed color) recorded in $\mathrm{CH}_{2} \mathrm{Cl}_{2}\left(\mathrm{C}=5 \times 10^{-6} \mathrm{M}\right)$, along with rotatory strengths for selected transitions (grey bars) and full predicted spectra (black curves) from TD-DFT calculations. E) Experimental emission spectra (dashed curves) recorded in $\mathrm{CH}_{2} \mathrm{Cl}_{2}(\mathrm{C}=$ $5 \times 10^{-5} \mathrm{M}$ ), along oscillator strength for $\mathrm{S}_{1} \rightarrow \mathrm{S}_{0}$ transition (bars) and predicted spectra (full curves) from TD-DFT calculations. F) Switch of glum value for (+)-C-29. 1: initial solution $\left(\mathrm{C}=5 \times 10^{-5} \mathrm{M}_{\text {in }} \mathrm{CH}_{2} \mathrm{Cl}_{2}\right) 2$ and 4: after protonation by addition of $4 \mathrm{mmol}$ of TFA; 3 and 5 : after addition of $4 \mathrm{mmol}$ of DBU. 
For (+)-C-29, a strong positive band around $320 \mathrm{~nm}\left(\Delta \varepsilon=150 \mathrm{M}^{-1} \mathrm{~cm}^{-1}\right)$, a lower one at $280 \mathrm{~nm}(\Delta \varepsilon=72$ $\left.\mathrm{M}^{-1} \mathrm{~cm}^{-1}\right)$ and another intense negative band at $230 \mathrm{~nm}\left(\Delta \varepsilon=166 \mathrm{M}^{-1} \mathrm{~cm}^{-1}\right)$ were observed (Figure $4 \mathrm{C}$, full blue curve). Three others bands of lower intensity were also visible at $350 \mathrm{~nm}\left(\Delta \varepsilon=23 \mathrm{M}^{-1} \mathrm{~cm}^{-1}\right)$, $400 \mathrm{~nm}\left(\Delta \varepsilon=7 \mathrm{M}^{-1} \mathrm{~cm}^{-1}\right)$ and $430 \mathrm{~nm}\left(\Delta \varepsilon=8 \mathrm{M}^{-1} \mathrm{~cm}^{-1}\right)$. After protonation to (+)-C-29• $\mathrm{H}^{+}$, major changes to the ECD spectra were observed (Figure 4D, full orange curve), notably with the appearance of a new positive band at $255 \mathrm{~nm}\left(\Delta \varepsilon=30 \mathrm{M}^{-1} \mathrm{~cm}^{-1}\right)$ and the sign change of the band situated at $280 \mathrm{~nm}(\Delta \varepsilon=35$ $\mathrm{M}^{-1} \mathrm{~cm}^{-1}$ ). The computational $\mathrm{CD}$ spectra (black curves in Figure $4 \mathrm{C}$ and $\mathrm{D}$ ) reproduce the experimental bands' energies, intensities, and sign changes with excellent agreement, except for lower-energy transitions (see below). In addition, the calculations agree that the lowest-energy transition of C-29 displays a positive $\Delta \varepsilon$, while that of $\mathbf{C}-\mathbf{2 9} \bullet \mathbf{H}^{+}$is negative, indicated by rotatory strengths of opposite sign.

In terms of emission properties, C-29 shows an intense blue fluorescence in dichloromethane with a maximum of emission at $436 \mathrm{~nm}$ (Figure $4 \mathrm{E}$, dashed blue line) and a $\Phi_{\mathrm{F}}=0.17$. An important red shift is observed for $\mathbf{C}-\mathbf{2 9} \cdot \mathrm{H}^{+}$compared to its basic form, resulting in a maximum of emission at $585 \mathrm{~nm}$ $\left(\Phi_{\mathrm{F}}=0.10\right)$ with again a fluorescence profile characteristic of intramolecular charge transfer (ICT, Figure $4 \mathrm{E}$, dashed orange curve).

The TD-DFT calculations predict a $\mathrm{S}_{0} \rightarrow \mathrm{S}_{1}$ absorption transition at $424 \mathrm{~nm}$ for $\mathrm{C}-\mathbf{2 9}$, and at $538 \mathrm{~nm}$ for C-29• $\mathrm{H}^{+}$and $\mathrm{S}_{1} \rightarrow \mathrm{S}_{0}$ fluorescence transitions at 473 and $641 \mathrm{~nm}$, respectively. As such, calculations agree with the experiments that the protonated helicene absorbs and emits at longer wavelengths than its unprotonated counterpart. For both compounds, the $S_{0}$ state corresponds to the $\pi$ HOMO, while the $S_{1}$ state is the $\pi^{*}$ LUMO, and the $S_{0} \rightarrow S_{1}$ Natural Transition Orbitals (NTOs) reproduce the Natural Bond Orbitals (NBOs) for the HOMO and LUMO (see SI). Inspection of the orbital energies show that protonation of the pyridine-like nitrogen greatly stabilizes the LUMO of $\mathbf{C}-\mathbf{2 9} \bullet \mathbf{H}^{+}$, while it has a smaller effect on its HOMO energy, lowering the HOMO-LUMO gap overall (see $\mathrm{SI}$ ) and explaining the important red shift of the fluorescence upon protonation. Moreover, the $S_{0} \rightarrow S_{1}$ transitions have an ICT character, especially in the case of $\mathbf{C}-\mathbf{2 9} \bullet \mathbf{H}^{+}$. As shown in Figure $4 A$ and $B$, the HOMOs show larger electron densities in the pyrazole ring and polycyclic structure emanating from the sydnone cycloaddition partner, while the LUMOs show more density in and around the pyridine ring system. Isosurfaces of the density can be found in the SI. Overall, only in the case of transitions with an ICT character does the experimental and computational spectra diverge, a known consequence of TD-DFT underestimating the energy of ICT transitions. ${ }^{33}$ The source of the discrepancy between experimental and computational transition energies might also be due to the fact that vibronic contributions were not included in the calculations, but are of significance for helicenes. ${ }^{34}$

The effect of protonation was found to be even more pronounced at the excited state when measuring the CPL signals. Indeed, the important red shift of the fluorescence occurring upon protonation is accompanied by a sign reversal of CPL emitted. Whereas (+)-C-29 displays a positive CPL signal with a $\lambda_{\text {em }}(\max )$ around $430 \mathrm{~nm},(+)-C-29 \bullet \mathrm{H}^{+}$shows a negative CPL response with a $\lambda_{\mathrm{em}}(\max )$ around $585 \mathrm{~nm}$ (Figure S10). Accordingly, the $g_{\text {lum }}$ values of (+)-C-29 in dichloromethane were measured at room temperature with a maximum of $+1.1 \times 10^{-3}$ at $430 \mathrm{~nm}$, whereas the maximum value for $(\mathbf{+})-\mathbf{C}-\mathbf{2 9} \bullet \mathbf{H}^{+}$is $-1.2 \times 10^{-3}$ at $585 \mathrm{~nm}$ (Figure S9). The TD-DFT calculations reproduce the sign and magnitude of the $g_{\text {lum }}$ measured experimentally. The luminescence dissymmetry factor $g_{\text {lum }}$ of a given transition (e.g. $S_{1}$ to $S_{0}$ ) is given by the equation $g_{\text {lum }}=4 R_{1-0} / D_{1-0}$, where $R=\left\|\mu_{\mathrm{e}}\right\| \cdot\left\|\mu_{\mathrm{m}}\right\| \cos \theta$ is the transition rotatory strength, $\mathrm{D}=\left\|\mu_{\mathrm{e}}\right\|^{2}$ is the transition dipole strength, $\mu_{\mathrm{e}}$ and $\mu_{\mathrm{m}}$ are the electric and magnetic transition 
dipole moments, respectively, and $\theta$ the angle between the dipole vectors. ${ }^{35}$ Using the computed $\mathrm{R}_{1-0}$ and $D_{1-0}$ for the $S_{1} \rightarrow S_{0}$ transitions of both $\mathrm{C}-29$ and $\mathbf{C}-29 \bullet \mathrm{H}^{+}$, the predicted glum values are $6.6 \times 10^{-4}$ at $473 \mathrm{~nm}$ for C-29 (expmtl: $\left.7.1 \times 10^{-4}\right)$, and $-7.8 \times 10^{-4}$ at $641 \mathrm{~nm}$ for $\mathbf{C}-29 \bullet \mathbf{H}^{+}\left(\operatorname{expmtl}:-8.5 \times 10^{-4}\right)$.

The reversibility of this $\mathrm{pH}$-triggered switch has been followed by UV/Vis and CPL measurements upon portion-wise addition of TFA and DBU. After 3 switches we confirmed that we could completely recover the CPL signals with no deterioration of the sample (Figure 4F). To the best of our knowledge, only one example of CPL sign inversion in chiroptical switches based on non-self-assembled small organic molecules (SOMs) has been described in the literature so far. ${ }^{36}$ This is a particularly interesting feature because CPL switches based on SOMs are generally of the on/off type, while keeping a CPL signal on in both switchable states is highly desirable for potential applications. ${ }^{4}$ The origin for this change of sign upon protonation can be understood by a slight change of the angle $\theta$ between the electric and magnetic transition dipoles, as shown in Figure 5. Indeed, the value of $\theta$ for the $S_{1} \rightarrow S_{0}$ transition of C29 is $85.9^{\circ}$, whereas that angle for $\mathbf{C}-\mathbf{2 9} \bullet \mathbf{H}^{+}$is $97.2^{\circ}$. Interestingly, the transition magnetic dipole for these compounds is aligned with the helical direction, while the electric dipole is aligned in the direction of the charge transfer. Both compounds however show similar values of $\left|g_{\text {lum }}\right|$. The real effect of protonating the pyridine-like nitrogen of $\mathbf{C - 2 9}$ is a slight change in the direction of the charge transfer and of $\mu_{\mathrm{e}}$, which affects the sign of $\cos \theta$ and thus the transition's rotatory strength, $\mathrm{R}_{1-0}$.
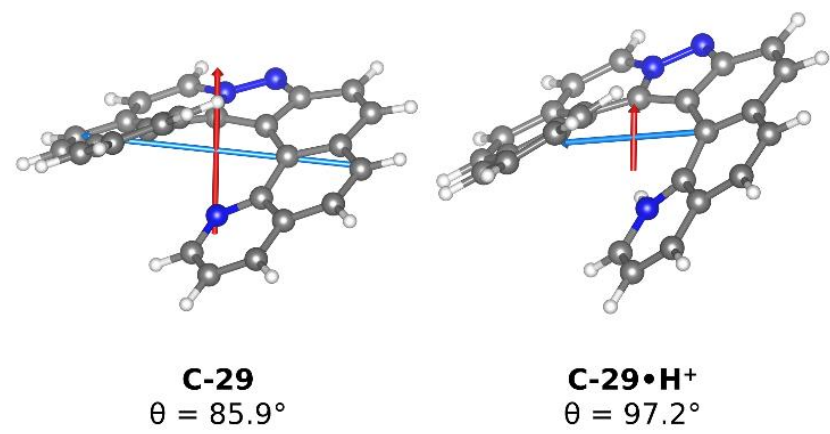

Figure 5. Magnetic (red) and electric (blue) transition dipoles for the $\mathrm{S}_{1} \rightarrow \mathrm{S}_{0}$ transition of $\mathbf{C}-\mathbf{2 9}$ and $\mathbf{C}-\mathbf{2 9} \bullet \mathbf{H}^{+}$.

We have also characterized the (chir)optical properties of helicene C-30 (see SI). Interestingly, in this case the fluorescence was also red shifted upon protonation the sign of the CPL emitted was not reversed. Indeed, the $\left|g_{\text {lum }}\right|$ values were in the same range of $1.3 \times 10^{-3}$ at $447 \mathrm{~nm}$ and of $1.5-1.9 \times 10^{-3}$ at $615 \mathrm{~nm}$ after acidic treatment. The current results showcase that the development of chiroptical switchs displaying CPL sign inversion such as C-29 is challenging, due to the influence of the substitution pattern or/and the nature of the heterocycles composing the helicene framework on the magnitude and orientation of magnetic and electric transition dipole moments (at both ground and exited states).

\section{Conclusion}

We have developed a versatile platform to assemble heterohelicene derivatives based on a regioselective 1,3-dipolar cycloaddition between poly-aromatic sydnones and arynes. A novel access to polycyclic sydnones and poly-(hetero)aromatic aryne precursors allowed to introduce chemical diversity over multiple positions of the helical scaffolds. The origin of the regioselectivity of the 
cycloaddition was investigated using DFT calculations, identifying face-to-face $(\pi \ldots \pi)$ or edge-to-face $(\mathrm{C}-\mathrm{H} . . . \pi)$ interactions, primary orbital interactions and distortion from coplanarity in the TS of the transformation as key factors. The synthetic methodology allowed to assemble a library of 24 heterohelicenes. In particular, a pyridyl-containing derivative displayed reversible, red-shifted, pH-triggered chiroptical switching properties, with CPL-sign reversal. The nature of this $\mathrm{pH}$-dependent behavior, on the same enantiomer and in the absence of transition metals, was studied by TD-DFT calculations. The CPL switch is caused by a change in the direction of ICT upon protonation, affecting the angle between the electric and magnetic transition dipole vectors and ultimately the sign of the transition rotatory strength.

\section{Acknowledgements}

This work was supported by CEA and ANR (ANR-17-CE07-0035-01). The authors thank T. d'Anfray, A. Goudet, S. Lebrequier and D.-A. Buisson (DRF-JOLIOT-SCBM, CEA) for the excellent analytical support and Dr. L. Plougastel and S. Gabillet for preliminary experiments. Computations presented in this work were performed on the Kong cluster at NJIT. We wish to thank as well Prof K. N. Houk (University of California, Los Angeles) for his mentorship over the course of this project.

\section{References}

[1] (a) C.-F. Chen, Y. Shen, Helicene Chemistry, Springer.; 2017. (b) M. Gingras, Chem. Soc. Rev. 2013, 42, 968-1006. (c) M. Gingras, G. Félix, R. Peresutti, Chem. Soc. Rev. 2013, 42, 10071050. (d) M. Gingras, Chem. Soc. Rev. 2013, 42, 1051-1095.

[2] (a) K. Dhbaibi, L. Favereau, J. Crassous, Chem. Rev. 2019, 119, 8846-8953. (b) E. S. Gauthier, R. Rodríguez, J. Crassous, Angew. Chem. Int. Ed. 2020, 59, 22840-22856.

[3] M. Rickhaus, M. Mayor, M. Juríček, Chem. Soc. Rev. 2016, 45, 1542-1556.

[4] J.-L. Ma, Q. Peng, C.-H. Zhao, Chem. Eur. J. 2019, 25, 15441-15454.

[5] H. Isla, J. Crassous, C. R. Chimie 2016, 19, 39-49.

[6] (a) H. Isla, N. Saleh, J.-K. Ou-Yang, K. Dhbaibi, M. Jean, M. Dziurka, L. Favereau, N. Vanthuyne, L. Toupet, B. Jamoussi, M. Srebro-Hooper, J. Crassous, J. Org. Chem. 2019, 84, 5383-5393. (b) N. Saleh, B. Moore II, M. Srebro, N. Vanthuyne, L. Toupet, J. A. G. Williams, C. Roussel, K. K. Deol, G. Muller, J. Autschbach, J. Crassous, Chem. Eur. J. 2015, 21, 1673-1681. (c) S. Pascal, C. Besnard, F. Zinna, L. Di Bari, B. Le Guennic, D. Jacquemin, J. Lacour, Org. Biomol. Chem. 2016, 14, 4590-4594. (d) T. Otani, A. Tsuyuki, T. Iwachi, S. Someya, K. Tateno, H. Kawai, T. Saito, K. S. Kanyiva, T. Shibata, Angew. Chem. Int. Ed. 2017, 56, 3906-3910.

[7] S. K. Pedersen, K. Eriksen, M. Pittelkow, Angew. Chem. Int. Ed. 2019, 58, 18419-18423.

[8] C. Shen, M. Srebro-Hooper, M. Jean, N. Vanthuyne, L. Toupet, J. A. G. Williams, A. R. Torres, A. J. Riives, G. Muller, J. Autschbach, J. Crassous, Chem. Eur. J. 2017, 23, 407-418.

[9] D. C. Harrowven, I. L. Guy, L. Nanson, Angew. Chem. Int. Ed. 2006, 45, 2242-2245.

[10] M. Weimar, R. Correa da Costa, F.-H. Lee, M. J. Fuchter, Org. Lett. 2013, 15, 1706-1709. 
[11] T. Otani, T. Sasayama, C. Iwashimizu, K. S. Kanyiva, H. Kawai, T. Shibata, Chem. Commun. 2020, 56, 4484-4487.

[12] (a) J. Nejedlý, M. Šámal, J. Rybáček, M. Tobrmanová, F. Szydlo, C. Coudret, M. Neumeier, J. Vacek, J. Vacek Chocholoušová, M. Buděšínský, D. Šaman, L. Bednárová, L. Sieger, I. G. Stará, I. Starý, Angew. Chem. Int. Ed. 2017, 56, 5839-5843. (b) M. Tanaka, Y. Shibata, K. Nakamura, K. Teraoka, H. Uekusa, K. Nakazono, T. Takata, K. Tanaka, Chem. Eur. J. 2016, 22, 9537-9541. (c) K. Tanaka, N. Fukawa, T. Suda, K. Noguchi, Angew. Chem. Int. Ed. 2009, 48, 5470-5473. (d) I. G. Stará, I. Starý, Acc. Chem. Res. 2020, 53, 144-158.

[13] E. Yen-Pon, P. A. Champagne, L. Plougastel, S. Gabillet, P. Thuéry, M. Johnson, G. Muller, G. Pieters, F. Taran, K. N. Houk, D. Audisio, J. Am. Chem. Soc. 2019, 141, 1435-1440.

[14] (a) Y. Fang, C. Wu, R. C. Larock, F. Shi, J. Org. Chem. 2011, 76, 8840-8851. (b) C. Wu, Y. Fang, R. C. Larock, F. Shi, Org. Lett. 2010, 12, 2234-2237. (c) J. M. Medina, J. L. Mackey, N. K. Garg K. N. Houk, J. Am. Chem. Soc. 2014, 136, 15798-15805. (d) N. F. Fine Nathel, L. A. Morrill, H. Mayr, N. K. Garg, J. Am. Chem. Soc. 2016, 138, 10402-10405. (e) T. K. Shah, J. M. Medina, N. K. Garg, J. Am. Chem. Soc. 2016, 138, 4948-4954. (f) A. Padwa, E. M. Burgess, H. L. Gingrich, D. M. Roush, J. Org. Chem. 1982, 47, 786-791. (g) T. C. McMahon, J. M. Medina, Y.-F. Yang, B. J. Simmons, K. N. Houk, N. K. Garg, J. Am. Chem. Soc. 2015, 137, 4082-4085.

[15] (a) K. N. Houk, J. Sims, R. E. Duke, R. W. Strozier, J. K. George, J. Am. Chem. Soc. 1973, 95, 7287-7301. (b) K. N. Houk, J. Sims, C. R. Watts, L. J. Luskus, J. Am. Chem. Soc. 1973, 95, 73017315. (c) P. A. Champagne, K. N. Houk, J. Org. Chem. 2017, 82, 10980-10988.

[16] X.-H. Liu, H. Park, J.-H. Hu, Y. Hu, Q.-L. Zhang, B.-L. Wang, B. Sun, K.-S. Yeung, F.-L. Zhang, J.-Q. Yu, J. Am. Chem. Soc. 2017, 139, 888-896.

[17] L. Li, H. Wang, X. Yang, L. Kong, F. Wang, X. Li, J. Org. Chem. 2016, 81, 12038-12045.

[18] A. V. Kelleghan, C. A. Busacca, M. Sarvestani, I. Volchkov, J. M. Medina, N. K. Garg, Org. Lett. 2020, 22, 1665-1669.

[19] D. Peña, D. Pérez, E. Guitián, L. Castedo, J. Org. Chem. 2000, 65, 6944-6950.

[20] T. Yamaki, T. Kato, M. Kawamura, H. Ito, US 2018/0219157 Al.

[21] (a) A. Fürstner, V. Mamane, J. Org. Chem. 2002, 67, 6264-6267. (b) V. Mamane, P. Hannen, A. Fürstner, Chem. Eur. J. 2004, 10, 4556-4575.

[22] A. Urbano, A. M. del Hoyo, A. Martínez-Carrión, M. C. Carreño, Org. Lett. 2019, 21, 46234627.

[23] (a) J. Chen, B. Captain, N. Takenaka, Org. Lett. 2011, 13, 1654-1657. (b) J. Klívar, M. Šámal, A. Jančařík, J. Vacek, L. Bednárová, M. Buděšínský, P. Fiedler, I. Starý, I. G. Stará, Eur. J. Org. Chem. 2018, 2018, 5164-5178. (c) J. Vacek Chocholoušová, J. Vacek, A. Andronova, J. Míšek, O. Songis, M. Šámal, I. G. Stará, M. Meyer, M. Bourdillon, L. Pospíšil, I. Starý, Chem. Eur. J. 2014, 20, 877-893. (d) J. Klívar, A. Jančařík, D. Šaman, R. Pohl, P. Fiedler, L. Bednárová, I. Starý, I. G. Stará, Chem. Eur. J. 2016, 22, 14401-14405.

[24] D. C. Powers, M. A. L. Geibel, J. E. M. N. Klein, T. Ritter, J. Am. Chem. Soc. 2009, 131, 1705017051.

[25] H. Noda, J. W. Bode, J. Am. Chem. Soc. 2015, 137, 3958-3966. 
[26] Although int2 is a minimum and TS3 is located at the optimization level of theory, it is likely that $\mathrm{CO}_{2}$ expulsion occurs spontaneously after TS2, as TS3 is found to have a lower energy than int2 at the highest level of theory.

[27] E. H. Krenske, K. N. Houk, Acc. Chem. Res. 2013, 46, 979-989.

[28] D. H. Ess, K. N. Houk, J. Am. Chem. Soc. 2008, 130, 10187-10198.

[29] F. M. Bickelhaupt, K. N. Houk, Angew. Chem. Int. Ed. 2017, 56, 10070-10086.

[30] (a) T. Lu, F. Chen, J. Comput. Chem. 2012, 33, 580-592. (b) F. L. Hirshfeld, Theor. chim. acta 1977, 44, 129-138.

[31] J. Wang, B. Durbeej, J. Comput. Chem. 2020, 41, 1718-1729.

[32] Full computational spectra are available in the SI.

[33] This drawback is well-documented, see: (a) A. Dreuw, M. Head-Gordon, J. Am. Chem. Soc, 2004, 126, 4007-4016; (b) J. Autschbach, ChemPhysChem 2009, 10, 1757-1760; (c) P. Zhou, J. Liu, S. Yang, J. Chen, K. Han, G. He, Phys. Chem. Chem. Phys. 2012, 14, 15191-15198.

However, when we used long-range-corrected DFT functionals to recalculate the absorbance spectra, the energy of the ICT states was now overestimated, leading to poorer agreement with experiment (see SI).

[34] (a) K. Dhbaibi, L. Favereau, M. Srebro-Hooper, C. Quinton, N. Vanthuyne, L. Arrico, T. Roisnel, B. Jamoussi, C. Poriel, C. Cabanetos, J. Autschbach, J. Crassous, Chem. Sci. 2020, 11, 567-576.

(b) K. Dhbaibi, C. Shen, M. Jean, N. Vanthuyne, T. Roisnel, M. Górecki, B. Jamoussi, L. Favereau, J. Crassous, Chiral Diketopyrrolopyrrole-Helicene Polymer With Efficient Red Circularly Polarized Luminescence. Front. Chem. 2020, 8, DOI: 10.3389/fchem.2020.00237.

[35] (a) H. Tanaka, M. Ikenosako, Y. Kato, M. Fujiki, Y. Inoue, T. Mori, Commun. Chem. 2018, 1, 38. https://doi.org/10.1038/s42004-018-0035-x. (b) B. Pritchard, J. Autschbach, ChemPhysChem 2010, 11, 2409-2415.

[36] S. Tong, J-T. Li, D-D. Liang, Y-E. Zhang, Q-Y. Feng, X. Zhang, J. Zhu, M-X. Wang, J. Am. Chem. Soc. 2020, 142, 14432-14436. 